\title{
Application and safety assessment for nano-composite materials in food packaging
}

\author{
HAN Wei ${ }^{1,2}$, YU YanJun ${ }^{1,2}$, LI NingTao ${ }^{1,2} \&$ WANG LiBing ${ }^{3 *}$ \\ ${ }^{1}$ The Hazardous Products Central Laboratory, General Administration of Quality Supervision, Inspection and Quarantine of the People's Republic \\ of China, Tianjin 300042, China; \\ ${ }^{2}$ Technical Center for Safety of Industrial Products, Tianjin Entry-Exit Inspection and Quarantine Bureau of China, Tianjin 300042, China; \\ ${ }^{3}$ Hunan Entry-Exit Inspection and Quarantine Bureau of China, Changsha 410004, China
}

Received April 21, 2010; accepted December 1, 2010

\begin{abstract}
The technical breakthroughs and rapid developments in nanotechnologies enabling goods and products based on nanomaterials (NMs) has come to media and public attention as potentially one of the most significant technological advances of our time. Among these technical applications, nano-composite food packaging, which combines the NMs and conventional packaging, is at the forefront of applications in nanotechnologies, leading the whole industrial chain based on nanotechnologies with high speed development. Taking into account the status of the nano-composites applied in food packaging and present development trends, this review is focused on summarizing the basic applications of the nano-composites in food packaging as well as its risk assessment. The status summaries and the conclusions derived from this review are of benefit to manufacturers which produce the nano-composites used in food packaging, to general consumers and to governmental administration entities.
\end{abstract}

nanometerials, composites, nano-composite materials, food packaging, safety assessment

Citation: Han W, Yu Y J, Li N T, et al. Application and safety assessment for nano-composite materials in food packaging. Chinese Sci Bull, 2011, 56: 1216-1225, doi: 10.1007/s11434-010-4326-6

Nanotechnology has been the subject of rapid expansion in the development and application of food packaging in recent years. In the process of food manufacturing, the additive surface functional nanoparticles (NPs), which are characterized by small size $(\leqslant 100 \mathrm{~nm})$, large surface area, and a high surface reactive property, can significantly improve food flavor, color and texture. They also increase nutrition absorption and food bioavailability, and bring human health benefits [1-4]. In the area of food packaging, the nano-composite, which combines the traditional food packaging materials with the NMs, has been subject to high speed development in the food packaging market with its excellent mechanical performance and good antibacterial and stronger resistant properties [5]. Reviewing the whole food manufacturing chain, the nanotechnologies used in food processing are more abundant than those in food

*Corresponding author (email:wanglb@hnciq.gov.cn) packaging. The reason for this status is that most people are dubious about the use of NMs before its safety is confirmed by reliable and convincing theoretical assessment and experimental data. In addition, from a technical viewpoint, the manufacturing methods and skills in combining NMs into packaging materials, such as polymers, paper and paperboard, glass and ceramic, and the surface of metals, are well developed. This is particularly true when compared with the current level of manufacturing methods and skills applied in nanostructured (or nanotextured) food ingredients, the delivery system for nutrients and supplements, and the nano-encapsulations of food ingredients and additives.

According to the market study report accomplished by Helmut Kaiser Consultancy in 2007, the type of the nanocomposites food packaging products expanded from less than 40 in 2002 to more than 400 in 2006 . In the next decade nanotechnology will impact $25 \%$ of the food packaging market, which is currently estimated at $\$ 100$ billion 
(www.foodproductiondaily.com/Packaging/Future-nanopackaging-market-worth-billions-says-study). The reason for this is that the general public thought the use of "fixed" NPs in food packaging materials was relatively safe and would not affect the quality of packed food. However, theoretical and experimental data simultaneously demonstrated that the NP composites used in packaging had the potential and tendency to migrate to food [6]. Also, the scientific reports conducted by the United States, European Union (EU), Japan, South Korea and China indicated that NMs have health and environment toxicities, which are dependent on its physicochemical characteristics such as size, morphology, and surface properties [7]. These raised public concern about NMs. As a result, the 6th Meeting of REACH in Brussels in December 2008 reached the conclusion that NMs were industrial materials and has taken them into its range of supervision.

This review summarizes the research literature, scientific reports, and resources of the internet on the applications of NMs in food packaging. Based on the results, a safety assessment for the use of NMs in food packaging is developed. This review is beneficial to the manufacturers which produce nano-composites used in food packaging, to general consumers and to governmental administration and supervision entities.

\section{Applications in food packaging}

According to laboratory research, market-oriented applications and development trends, three main categories of nanotechnology are used in food packaging applications: NPs-reinforced packaging, active and intelligent packaging, and biodegradable nano-composites food packaging.

\subsection{NPs-reinforced packaging}

The high surface area enables NPs to dramatically improve the mechanical performance, such as flexibility, reduced gaseous permeation, stability of temperature and humidity, and ultraviolet light and flame resistance, of packaging materials with a relatively low mass content $(\sim 5 \%$, w/w). In 2001, nano-composites constructed by polymer and nanosized montmorillonite (MMT) have been shown to improve the thermal-resistance properties of packaging materials [9]; composites made of polylactic acid (PLA) and nano-sized MMT could improve the fire-resistance [10]; polyethylene (PE)-MMT and PE-silica $\left(\mathrm{SiO}_{2}\right)$ composites improved durability [11]; a nano-composite synthesized by polyvinyl chloride (PVC) and MMT could improve the property of optical resistance [12]. A novel composite prepared by polyamide and multiwall carbon nanotube (MWNT) offered significant flame-resistant properties [13]; another composite composed of polymer and nano-sized MMT improved gas barrier properties [14]. The variety of NP-reinforced polymers has attracted increasing attention, and nanocomposites use in food packaging has become the most developed area in nanotechnology [15].

Apart from improving mechanical properties, the application of NPs can bring extra functions, such as an antibacterial property, to food packaging. Silver (Ag) NPs are the most frequently used material for the purpose of providing an antibacterial property [16-18]. Ag NPs used in packaging or food contact materials can prolong foodstuff shelf life by restraining the growth of bacteria. For example, the NPs-polymer composites can form coatings on the surface of tableware and kitchenware to inhibit the growth of microorganisms. Examples of this type of tableware and kitchenware are found in products made by Nano Care Technology in China (www.nanocaretech.com/En_ArticleShow.asp?ArticleID=13) and A-DO in South Korea (www.adox.info/?doc=shop/list.php\&ca_id=150110). Recently, researchers from the University of Leeds, UK, discovered the antimicrobial properties of nano-zinc oxide $(\mathrm{ZnO})$ and magnesium oxide (MgO). Compared with Ag NPs, the $\mathrm{ZnO}$ and $\mathrm{MgO}$ NPs are expected to provide not only more affordable and safe food packaging solutions in the future, but also a greater ability to inhibit the growth of microorganisms (www.foodproductiondaily.com/Packaging/Nanotech -discovery-promises-safer-food-packaging). An example is SongSing Nano Technology Co. Ltd., which introduced the oxide-based light catalyst $\mathrm{ZnO}$ NPs into their plastic wrap, which claimed to sterilize under indoor lighting (www.nanotechproject.org/inventories/consumer/browse/products/nano_plastic_-wrap/). More examples for $\mathrm{Ag}$ and $\mathrm{ZnO}$ NPs used in food contact materials are summarized in Table 1 , with products manufactured by large companies such as Bayer and Honeywell.

\subsection{Active and intelligent food packaging}

The active and intelligent food packaging category is a novel type of packaging compared with traditional methods. In active and intelligent food packaging, the "active" refers to the packaging which has the ability to remove undesirable tastes and flavor, and improve the color or smell of the packed food. For example, the incorporated carbon black (CB) NPs and MWNT in polymer packaging can absorb the smell emitted from the packaging or food; furthermore, an incorporated spice can preserve the color and smell of the food [19-21].

"Intelligent" food packaging seems to have a broader application than "active" packaging. In general, the "intelligent" aspect of food packaging refers to the concept of monitoring information about the quality of the packed food. For instance, packaging materials incorporating nano-sensors or nano-capsules based on nanotechnology will be able to detect food spoilage organisms and trigger a color change to alert the consumer that the shelf life is ending or has ended. This type of function can also incorporate 
Table 1 Selected market products with NP-reinforced properties

\begin{tabular}{|c|c|}
\hline Manufacturer & Application \& properties \\
\hline SongSing Nano Technology & Food cling wrap treated with ZnO NPs; tea pot treated with Ag NPs \\
\hline Sharper Image and BlueMoonGoods & FresherLonger ${ }^{\mathrm{TM}}$ Miracle Food Storage Containers and Plastic Storage Bags \\
\hline Baby Dream & Ag NPs baby milk bottle \\
\hline A-DO Global & Ag NP-coated cutting board \\
\hline Nanocor & $\begin{array}{l}\text { Branded with Imperm®. Used in multi-layer PET bottles for food and beverage packaging to minimize the loss of } \\
\qquad \mathrm{CO}_{2} \text { from the drink and the ingress of } \mathrm{O}_{2} \text { into the bottle }\end{array}$ \\
\hline Honeywell & $\begin{array}{l}\text { Branded with Aegis }{ }^{\circledR} \text { OX. Resin composed of nylon and MMT NPs, enhance barrier properties for retaining } \mathrm{CO}_{2} \\
\text { and keeping } \mathrm{O}_{2} \text { out. Used in PET bottles such as beer, fruit juice and soft drinks }\end{array}$ \\
\hline Bayer & $\begin{array}{l}\text { Branded with Durethan }{ }^{\circledR} \text { KU2-2601. Hybrid plastic comprises polyamide and layered silicate barriers. The plastic } \\
\text { incorporates Nanocor's MMT to produce a film with increased barrier properties, enhanced gloss and stiffness }\end{array}$ \\
\hline
\end{tabular}

a concept of "Release-on-Command", which will provide a basis for intelligent preservative packaging technology that will release a preservative if food begins to spoil (www.azonan-o.com/Details.asp?ArticleID=1317). In addition, packaging containing sensor arrays is another novel technique based on the concept of an "Electronic Tongue", which can monitor and signal the condition of the packed food [22]. More examples based on active and intelligent techniques are summarized in Table 2.

Among the new-market developments are NMs-based next generation packaging displays that include Radio Frequency Identification Display (RFID). These displays involve utilization of smart labels that will assist quick and accurate distribution of a wide variety of goods with limited shelf-life. Also under development are RFIDs incorporating polymeric transistors that use nanoscale organic thin-film technology. The RFID systems will be designed to operate automatically and will provide exception reports for anomalies such as temperature, short-life span products.

\subsection{Biodegradable nano-composite food packaging}

The biodegradable nano-composite food packaging category involves new types of biodegradable materials, which in general can be made of PLA and MMT. MMT is a type of relatively cheap and widely available natural clay derived from volcanic ash/rocks [23-26]. The naturally existing nano-layered structure limits the permeation of gases, and provides substantial improvements in gas barrier properties of the nano-composite. Such improvements have led to the development of PLA-MMT nano-composites for potential use in a variety of food-packaging applications, such as processed meats, cheese, confectionery, cereals, as well as boil-in-the-bag foods. In 2003, a novel nano-composite composed of biodegradable polymer and nano-sized MMT prepared by the McGlashan group offered excellent recycling properties [25]. Other successful applications in the market based on biodegradable nano-composites are summarized in Table 3.

\section{Safety assessment for nano-composite food packaging}

\subsection{Migration study}

The main risk of consumer exposure to NPs from food packaging is likely to be through potential migration of NPs into food and drink. However, migration experimental data are not currently available, despite the fact that a number of food packaging types containing NPs are already available and in commercial use in some countries.

The pioneering work was accomplished by a group led by Maurizio Avella from Italy in 2005. Nano-composite

Table 2 Packaging products based on active and intelligent techniques

\begin{tabular}{|c|c|}
\hline Manufacturer or Institution & Application \& properties \\
\hline CSP Technology & $\begin{array}{l}\text { Polymer capable of releasing ingredients into the food or beverage in response to external stimuli, to control hu- } \\
\text { midity, oxygen, bacteria, odor and even the flavor of the food itself }\end{array}$ \\
\hline Kraft & $\begin{array}{l}\text { Nano-sensor based "electronic tongue" able to "taste" chemicals to the level of parts per trillion and then guide } \\
\text { chemical release, to control the release of smell, taste and nutraceuticals into food products in response to the } \\
\text { preferences of individual consumers }\end{array}$ \\
\hline Georgia Technology & MWNT based biosensor, to detect microorganisms, toxic proteins, or spoilage of foods and some beverages \\
\hline $\begin{array}{l}\text { University of Southampton, UK \& } \\
\text { Deutsches Kunststoff-Institut, Germany }\end{array}$ & "Opal" film, incorporating $50 \mathrm{~nm} \mathrm{CB} \mathrm{NPs,} \mathrm{to} \mathrm{change} \mathrm{colour} \mathrm{in} \mathrm{response} \mathrm{to} \mathrm{food} \mathrm{spoilage}$ \\
\hline University of Strathclyde, Scotland & UV-light activated, $\mathrm{TiO}_{2} \mathrm{NPs}$ based, oxygen-sensing ink, for the purpose of tamper proofing \\
\hline Australian company MiniFAB & Nanotechnology based biosensors, to detect biological contamination \\
\hline
\end{tabular}


Table 3 Examples of packaging products based on biodegradable nano-composites

\begin{tabular}{cc}
\hline Manufacturer or Institution & Application \& properties \\
Plantic Technologies & $\begin{array}{c}\text { Nano-composite biopolymers. Supplied to 80\% of the Australian chocolate tray } \\
\text { market, including Cadbury Australia }\end{array}$ \\
Rohm and Haas & $\begin{array}{c}\text { Nano-composite biopolymers using Paraloid BPM-500, to strengthen PLA, a biodegradable } \\
\text { plastic resin made from corn, while maintaining the plastic's transparency } \\
\text { Nano-composite biopolymers using nano clay, to strengthen fiber-based, } \\
\text { biodegradable packaging, and to make the packaging water repellent } \\
\text { "Sustainpack": } 35 \text { research institutes, universities and } \\
\text { corporate partners from 13 European countries } \\
\text { Australia's Commonwealth Scientific and Industrial } \\
\text { Research Organization }\end{array}$ \\
\hline
\end{tabular}

films were obtained by homogeneously dispersing functionalized layered MMT NPs in different thermoplastic starches, such as neat potato starch and a mixture of potato starch with biodegradable polyester, via a polymer melt processing techniques [26]. The conformity of the nanocomposites with actual regulations and European directives on biodegradable materials was verified by migration tests. The vegetable samples, including lettuce and spinach, were cut into small samples and packed into bags for the contact-tests. Subsequently the closed bags were placed in an electrical furnace and heated to $40^{\circ} \mathrm{C}$ for 10 days. After this process, every bag was slowly cooled to the ambient temperature and submitted to subsequent characterization. The vegetable samples were digested by heating in a furnace at $105^{\circ} \mathrm{C}$ to constant weight, then carbonized in a muffle at $550^{\circ} \mathrm{C}$ for a few hours and cooled in a dry atmosphere for $40 \mathrm{~min}$. The ash obtained was dissolved in hydrochloride acid solution, put in a hot water bath and finally filtered. The filtrate was analyzed by atomic absorption equipment to measure the $\mathrm{Si}, \mathrm{Fe}$ and $\mathrm{Mg}$ release. The analyzed results demonstrated an insignificant trend in the levels of $\mathrm{Fe}$ and $\mathrm{Mg}$ in packaged vegetables, but a consistent increase in the amount of $\mathrm{Si}$, which is the main component of the MMT NPs.

A group from the Slovak University of Technology studied the NP migration based on the concept of chemical potential [6]. This study took into account physicochemical properties of both NPs and packaging polymers, such as the density of the polymer, the size of the NPs, the density of NPs in the polymer and the average distance of NPs from the surface of the polymer. They deduced the migratability, eq. (1), of NPs in polymer and the migration numbers, eq. (2), of NPs from the nano-composites making use of Fick's second law of diffusion:

$$
\begin{gathered}
m=\sqrt{\frac{k_{B} T t}{24 \pi^{2} \eta a}}, \\
n=m S c_{0} .
\end{gathered}
$$

In eq. (1), $m$ is the migratability of NPs in polymer, $k_{\mathrm{B}}$ is the Boltzmann constant $\left(k_{\mathrm{B}}=1.3807 \times 10^{-23} \mathrm{~J} / \mathrm{K}\right), a$ is the radius of NPs, $T$ stands for the absolute temperature, $t$ stands for the migration time and $\eta$ stands for the dynamic viscosity of the polymer. It can be seen that the migratabil- ity of NPs is controlled by the size of NPs and the density of the polymer matrix. The smaller size of NPs and smaller density of polymer will result in higher migratability. In eq. (2), $n$ stands for the amount of migrating NPs, $S$ stands for the surface area of the polymer film and $c_{0}$ is the initial concentration of NPs in the polymer film. By using eqs. (1) and (2), they calculated $m$ and $n$ for different NPs with various radii and polymer with different densities. Taking the surface area as $0.2 \mathrm{~m}^{2}$ of low density PE (LDPE) and $5 \mathrm{~nm} \mathrm{Ag}$ NPs as example, provided that the initial concentration of the NPs in LDPE is $1 \mathrm{~kg} / \mathrm{m}^{3}$, the calculated migratability at a temperature of $25^{\circ} \mathrm{C}$ in LDPE is $1.3 \times 10^{-6}$, and the amount of the migrating NPs is $2.6 \times 10^{-7} \mathrm{~kg}$ within 1 year. In the case of polyethylene terephthalate (PET), the amount of migrating NPs is less than $2.2 \times 10^{-9} \mathrm{~kg}$. These theoretical calculations indicated the migration of NPs in nano-composites strongly depends on its size and the density of the matrix.

Migration studies of NPs in food contact materials are relative scarce. The difficulties in characterizing NPs in composites and the lack of methods for qualitative and quantitative analysis are responsible for this limited research on migrating of NPs in nano-composites.

\subsection{Sources and distribution}

According to the scientific report from the European Centre for Ecotoxicology and Toxicology of Chemicals, there are three main routes for human exposure to NPs: inhalation, dermal contact and oral ingestion [27]. The atmosphere within and around workplaces in the manufacturing process is the source of exposure. After inhalation, the NPs will deposit within the respiratory system (mainly the lung) by diffusion. General speaking, the smaller NPs have a higher probability of affecting the epithelium of the lung structure. Insoluble NPs larger than $100 \mathrm{~nm}$, will move, by the action of ciliated cells in the mucus, or by coughing, within 1-2 days, to the throat (larynx), where they are swallowed. However, small NPs will be taken up and digested by the specialized defense cells called macrophages, located in the alveoli. The interaction of NPs with the alveoli will transport NPs from luminal to the mucosal side of epithelial and endothelial cells by the function of vesicular caveolae. Transport within caveolae for small NPs exists across the 
alveolar capillary barrier as a pathway from the lung to the blood [28,29]. With the help of blood circulation, NPs will be transported to other systems such as the liver, spleen, kidney, brain and heart.

Uptake by skin contact can occur through three possible penetrating pathways: intercellular, intracellular, and follicular penetration. Among these, follicular penetration is a direct and effective way for NPs to be absorbed by the skin, even though the amount of hair follicles on the skin surface was estimated to be not more than $0.1 \%$ of the total skin surface area [30,31]. However, increasingly, studies are revealing that the NPs taken up by the skin remain on the surface of the stratum corneum or accumulate in the follicle orifices, whichever penetration pathway they take, but do not penetrate the skin or the follicle [32,33].

Oral uptake from food with added NPs, and any migrations from the nano-composites, is the most significant exposure source for human beings. The digested NPs will temporarily remain and accumulate in the gastrointestinal (GI) tract, and are then absorbed by the intestinal epithelium to be transported to other systems and organisms. Translocation of NPs through the intestinal wall is a multi-step process, involving diffusion through the mucus lining of the gut wall, contact with enterocytes or M-Cells, cellular or paracellular transport, and post-translocation events [34]. During the translocations, factors such as size, surface charge, lipophilicity/hydrophilicity, presence/absence of a ligand, and physiology of the intestinal tract, e.g., healthy vs. diseased state, will influence the translocation process [35].

Smaller particles are generally absorbed more readily and faster than larger ones. Diffusion across the preepithelial mucus gel layer of the distal colon of rats was conducted by Szentkuti's group in 1997, and the results demonstrated that $14 \mathrm{~nm}$ (average in diameter) PLA NPs cross within 2 minutes and $415 \mathrm{~nm}$ within 30 minutes, while $1000 \mathrm{~nm}$ did not cross this barrier [36]. Oral administration of Au-NP, with different sizes of 58, 28, 10 and $4 \mathrm{~nm}$, to mice, showed increased GI uptake with diminishing size [37]. The amount of absorption of polystyrene (PS) NPs of 50, 100, 200, 300, 1000 and $3000 \mathrm{~nm}$ has been shown to be $34 \%$ in rats at 50 $\mathrm{nm}$, and decreasing to almost zero with increasing size [38]. Passage of NPs through the intestinal mucus is not only dependant on the size, but also the surface charge. Furthermore, experiments by Szentkuti, with different charges diffused through intestinal mucus, showed that the cationic NPs were found to become entrapped within the negatively charged mucus, whereas carboxylated (anionic) NPs were able to diffuse successfully through to the epithelial surface [36]. Very recently, the researchers at John Hopkins University in Maryland, USA, discovered that pores within the mucus layer are much larger than originally anticipated, and NPs as large as $200 \mathrm{~nm}$ can pass through mucus pores when coated with polyethylene glycol (PEG) [39].

Once NPs have diffused through the gut mucosa and been in contact with enterocytes and M-cells, they will pass through the epithelia. There are several mechanisms by which NPs may pass through the epithelia: transcytosis by enterocytes, transcytosis by M-cells in Peyer's patches (PP) and passive diffusion across the epithelia or paracellular transport. The GI uptake rate of NPs is 2-200 times greater in PP than in enterocytes even though the PP represent only $\sim 1 \%$ of the total intestinal surface area [35]. The translocation of NPs in the epithelium is also dependant on their size. For example, translocation of NPs with an average size of $116 \pm 5 \mathrm{~nm}$ is $15-250$ times greater than that of microparticles, which are more likely to become lodged within the PP [35]. The GI absorption of NPs may be affected by different surface coatings and zeta potential.

Upon contact with the intestinal submucosal tissue, NPs can enter the capillaries, which will carry them through the portal circulation to the liver, or they enter the lymphatic system, which via the thoracic duct empties into the blood circulation system. In a 28-day rat oral study of $60 \mathrm{~nm}$ Ag-NPs, the highest Ag levels occurred in the stomach, followed by kidney and liver, lungs, testes, brain and blood [40]. The distribution is dependent upon the size of the NPs. In the administration of Au-NP sized 58, 28, 10 and $4 \mathrm{~nm}$ to mice, the smaller particle size resulted in increased distribution to the organs. The smallest NPs were found in the kidney, liver, spleen, lungs and brain, while the biggest remained almost solely inside the GI tract [37]. PS NPs ranging from $50 \mathrm{~nm}$ to $3 \mu \mathrm{m}$ were fed by gavage to female Sprague Dawley rats daily for 10 days at a dose of 1.25 $\mathrm{mg} / \mathrm{kg}^{-1}$. The extent of absorption of the $50 \mathrm{~nm}$ particles was $34 \%$ and of the $100 \mathrm{~nm}$ particles $26 \%$, of which about $7 \%(50 \mathrm{~nm})$ and $4 \%(100 \mathrm{~nm})$, was in the liver, spleen, blood and bone marrow.

\subsection{Toxicity}

The migration of NPs from packaging to packed food raised public concern, and had been corroborated by animal oral administration and in-vitro cell experiments. In general, two types of mechanism can be adopted to explain the toxicity effects on humans. One is that the toxicity is independent of the NPs, and could be realized by generating the active oxygen species (ROS) within the cells. Another is that the toxicity has a strong relationship with the chemical component of NPs. For example, the crystallization and recrystallization of some metal or metal oxide NPs will modify the secondary or tertiary conformation of the proteins. While other types of NPs, such as the metal alloy, or single-wall carbon nanotube (SWNT) or MWNT can result in direct or indirect gene toxicity.

In vitro experiments have shown that the NPs within cells will generate a large number of ROS. It is well known that shrinkage in a number of materials is responsible for the change in the physicochemical and electron structural of some NPs. For instance, the decrease in size of bulk materials 
may create discontinuous crystal planes and enable more atoms within the materials to be at the surface of the NPs, which increases the number of structural defects and dangling bonds as well as disrupting the well structured electronic configuration of the materials, giving rise to altered electronic properties [41,42]. The altered electronic structure establishes specific surface groups that could function as reactive sites. For instance, the altered electronic structures in semiconductor and metal NPs unbond the surface atom and within the electron-hole pair become the reactive sites. Electron capture within the reactive sites with molecular dioxygen $\left(\mathrm{O}_{2}\right)$ can lead to the formation of the superoxide radical $\mathrm{O}_{2}{ }^{-}$, which through dismutation or Fenton chemistry can generate additional ROS. The ROS generation is independent of the chemical compositions of NPs, i.e., NPs like the metal, metal alloy, metal oxides, semiconductors and nonmetal $\mathrm{CB}$ (including nanotube and fullerene $\left(\mathrm{C}_{60}\right.$ and $\left.\mathrm{C}_{70}\right)$ ) can generate the ROS within the cell. However, in normal conditions, the mitochondria in cells can generate the ROS at low frequency and are easily neutralized by antioxidant defenses such as glutathione (GSH) and antioxidant enzymes [43]. However, the presence of NPs, which will preferentially mobilize the mitochondria in cells, will interfere and alter the ROS production and thereby overload or interfere with the antioxidant defenses. The overwhelmed antioxidant defenses enable the cells to transform into a state in which the GSH is depleted while oxidized glutathione (GSSG) accumulates, which is called oxidative stress [43]. The oxidative stress can lead to a decrease in the ability of cells to form an antioxidant defense, and to the accumulation of GSSG, resulting in respiratory tract inflammation and interstitial fibrosis.

From a mechanistic perspective, ROS generation and oxidative stress is the best developed paradigm to explain the toxic effects of NPs. In 2003, a group lead by Nel in America studied the relationship between mean size, size distribution, and composition of NPs and their ability to induce oxidative stress [44]. The results indicate that the higher the monodispersion of NPs, the higher the volume of ROS will be generated and the stronger the oxidative stress upon the cells. At the same time, the research group led by Yamakoshi from Japan studied the process and mechanism of fullerene $\left(\mathrm{C}_{60}\right.$ and $\left.\mathrm{C}_{70}\right)$ generating ROS in cells, and quantitatively determined the content of $\operatorname{ROS}\left(\mathrm{O}_{2}{ }^{-}\right.$and ${ }^{\circ} \mathrm{OH}$ ) by biochemical (DNA-cleavage assay in the presence of various scavengers of active oxygen species) and physico-chemical (Electron Paramagnetic Resonance (EPR) radical trapping and near-infrared (NIR) spectrometry) means [45]. Oxidative stress can also influence the central nervous system. For example, an experimental study demonstrated that oxidative stress is implicated in the pathogenesis of neurodegenerative diseases such as Parkinson's and Alzheimer's [46]. Evidence for such effects is presented by studies on biopsies from city dwellers and Alzheimer-like pathology has demonstrated increased markers of inflammation and AB42-accumulation in the frontal cortex and hippocampus in association with the presence of NPs [47].

Toxicity induced by oral administration will influence the liver and spleen. The reticuloendothelial system located in the liver and spleen have the ability to phagocytose cellular debris, aged cells, pathogens and foreign substances including

Table 4 Experimental evidence of the toxicity of selected NMs in commercial applications

\begin{tabular}{|c|c|c|}
\hline NMs \& applications & Size \& physical description & Experimental evidence of toxicity \\
\hline \multirow{5}{*}{$\begin{array}{l}\mathrm{TiO}_{2} \text {, used as antimicrobial } \\
\text { and UV protector in } \\
\text { food packaging }\end{array}$} & $20 \mathrm{~nm}$ & Destroyed DNA \\
\hline & $30 \mathrm{~nm}$, mix of rutile and anatase forms & Produced free radicals in brain immune cells \\
\hline & NPs, mix of rutile and anatase forms & DNA damage to human skin cells when exposed to UV light \\
\hline & $\begin{array}{l}\text { Four sizes 3-20 nm, mix of rutile and ana- } \\
\text { tase form }\end{array}$ & $\begin{array}{l}\text { High concentrations interfered with the function of skin and lung cells. } \\
\text { Anatase particles } 100 \text { times more toxic than rutile ones }\end{array}$ \\
\hline & $25 \mathrm{~nm}, 80 \mathrm{~nm}, 155 \mathrm{~nm}$ & $\begin{array}{l}25 \mathrm{~nm} \text { and } 80 \mathrm{~nm} \text { particles caused liver and kidney damage in female } \\
\text { mice. } \mathrm{TiO}_{2} \text { accumulated in liver, spleen, kidneys and lung tissues }\end{array}$ \\
\hline \multirow{3}{*}{$\begin{array}{l}\text { Ag, used as antimicrobial in } \\
\text { food contact materials }\end{array}$} & $15 \mathrm{~nm}$ & Highly toxic to mouse germ-line stem cells \\
\hline & $15 \mathrm{~nm}, 100 \mathrm{~nm}$ & Highly toxic to rat liver cells \\
\hline & $15 \mathrm{~nm}$ & Toxic to rat brain cells \\
\hline \multirow{2}{*}{$\begin{array}{l}\mathrm{Zn} \text { and } \mathrm{ZnO} \text {, used as antimicrobial } \\
\text { in food packaging }\end{array}$} & $20 \mathrm{~nm}, 120 \mathrm{~nm} \mathrm{ZnO}$ powder & $\begin{array}{l}120 \mathrm{~nm} \text { particles caused dose-effect damage in mice liver, heart and } \\
\text { spleen. } 20 \mathrm{~nm} \text { particles damaged liver, spleen and pancreas }\end{array}$ \\
\hline & $19 \mathrm{~nm} \mathrm{ZnO}$ & Toxic to human and rat cells even at very low concentrations \\
\hline $\begin{array}{l}\mathrm{SiO}_{2} \text {, particles nano form touted for } \\
\text { use in food packaging }\end{array}$ & $\begin{array}{l}50 \mathrm{~nm}, 70 \mathrm{~nm}, 0.2 \mu \mathrm{m}, 0.5 \mu \mathrm{m} \\
1 \mu \mathrm{m}, 5 \mu \mathrm{m}\end{array}$ & $\begin{array}{c}50 \mathrm{~nm} \text { and } 70 \mathrm{~nm} \text { particles taken up into cell nucleus where they caused } \\
\text { aberrant protein formation and inhibited cell growth. Caused the onset of } \\
\text { a pathology similar to neurodegenerative disorders }\end{array}$ \\
\hline
\end{tabular}


inert particles from the blood stream. Such cells include macrophages, monocytes, and specialized endothelial cells that line the organs such as the liver, spleen and bone marrow. The main function of this system is thought to be the removal and neutralization of any potential pathogens that enter the body from the GI microflora. However, these cells have the capacity to phagocytose NPs. Evidence from in vitro studies that NPs such as CB and PS stimulate the macrophages via $\mathrm{ROS}$ and $\mathrm{Ca}$ signaling to make proinflammatory cytokines such as the tumor necrosis factor alpha [48]. Oxidative stress is known to inhibit the hepatocyte function and bile formation [49], while proinflammatory cytokines are also associated with the pathology of liver disease.

NPs through oral administration may create cardiovascular effects, which include heart rate changes, prothrombosis and acute myocardial infarction. For instance, research results derived from experiments led by Samuel on imaging angiogenesis by inter-intargeted paramagnetic iron oxide, demonstrated that cationic NPs, including Au and PS can cause hemolysis and blood clotting, while usually anionic NPs are quite nontoxic. Another experiment conducted by Campen's group, on hypertensive rats, showed that the rats with no oral administration displayed a reduced daytime heart rate from the beginning of the protocol, whereas exposed rats maintained a significantly elevated heart rate. Daytime heart rate values for male control rats averaged $265 \pm 5$ beats $/ \mathrm{min}$, whereas values for exposed rats averaged $290 \pm 7$ beats $/ \mathrm{min}$ [50]. In 2002, a test on the effect of exposure to NPs on the progress of atherosclerosis in rabbits was conducted by a research group from Canada. Results of that experiment indicated that a high dose of NPs in Watanabe rabbits caused morphological evidence of atheromatous plaque destabilization [51]. Ultrafine CB NPs digested into the blood has been reported to induce platelet accumulation in the hepatic microvasculature of healthy mice in association with prothrombotic changes on the endothelial surface of the hepatic microvessels [52]. Although several toxicological studies have demonstrated that the oral administration of NPs can gain access to the blood and can enhance experimental thrombosis, it is not clear whether this is a pulmonary inflammation or NPs translocated to the blood [47].

Some toxicities are dependent on the chemical composition of the NPs. For example, experimental results indicate that the accumulation of insoluble NPs in humans may be responsible for the compromised GI functionality, including irritable bowel disease (IBD) and Crohn's disease [53]. Although little is known about whether NPs are linked to the initiation of IBD and Crohn's disease, it seems that the NPs may be adjuvant triggers for the exacerbation of these diseases [54]. For instance, some insoluble NPs, such as $\mathrm{TiO}_{2}$, $\mathrm{ZnO}$ and $\mathrm{SiO}_{2}$, when they are absorbed by GI and pass through the intestinal tract, come into contact with and adsorb calcium ions and lipopolysaccharide. The resulting NPs-calcium-lipopolysaccharide conjugates activate both peripheral blood mononuclear cells and intestinal phagocytes, which are usually resistant to stimulation [55]. Metal or metal oxide NPs, such as $\mathrm{Fe} / \mathrm{Pt}$ alloy, $\mathrm{Co} / \mathrm{Cr}$ alloy, $\mathrm{ZnO}$, $\mathrm{SiO}_{2}, \mathrm{TiO}_{2}$, and $\mathrm{SWNT}$ and MWNT, present direct genotoxicity and indirect genotoxicity [56,57]. For $\mathrm{TiO}_{2}$ and $\mathrm{CB}$, it was reported that particles with a mean size of $\sim 20$ $\mathrm{nm}$ induced DNA damage, while larger particles $(\sim 200 \mathrm{~nm})$ did not $[56,58,59]$. Similar observations were reported for Co-NPs [60]. More research studies on toxicity are summarized in Table 4. From Table 4, one can see that the toxicity of NPs is strongly related to its chemical composition and particle sizes.

\section{Detection methods}

In contrast to techniques used for small organic molecular and inorganic compounds and the low-molecular-weight polymers, the techniques for NPs and NPs in nanocomposites are more sophisticated, typically because of the strong relationship between the functions of the packaging materials, and the toxicity morphologies in the packaging matrix. Therefore, apart from the traditional instrumental methods, other special means of determination such as imaging techniques are needed for successful characterization of NPs.

\subsection{Imaging techniques}

Imaging techniques for detection of NPs are mainly electronic microscope techniques and related facilities, such as transmission electron microscopy (TEM), scanning electron microscopy (SEM) and atomic force microscopy (AFM). In 2003, Morgan of Dow Chemicals, characterized the MMT $\mathrm{NP}$ dispersion in polymers by using TEM. The research nano-composites ranges include thermoset (cyanate esters) and thermoplastic polymers (PS, nylon 6, and polypropylene- $g$-maleic anhydride) [61]. Researchers from the CNRS in France characterized the size and shape of MMT NPs located within the PP-MMT composites made by using two different facilities. A statistical TEM image analysis methodology was developed to evaluate the different particle parameters (thickness, length, aspect ratio and interparticle distance). The results obtained showed a correlation between the size of the tactoids and the shear intensity [62]. In addition, Japanese researchers from Toyota observed the microstructures of the nano-composites of nylon-MMT with the help of SEM. The results revealed a novel structure, in which the layered MMT NPs stood perpendicularly to the nylon surface, resembling a vertical cliff [63]. PerrinSarazin group analyzed the shape and morphology of MMT NPs by simultaneously using TEM and SEM techniques [64]. In 2004, the group led by Cakmak synthesized a novel nano-composite composed of MMT NPs and PVC by using the dioctyl phthalate as the plasticizer. Characterizations by 
AFM revealed the layered MMT NPs lay preferentially on their basal surfaces. The microstructure analysis implied that if the plasticizer was used in high concentrations, the ability to transfer forces to the MMT NPs through the polymer matrix decreases due to a substantial decrease in viscosity [65].

\subsection{Characterization techniques}

The qualitative determination of NPs in nano-composites can be realized by applying X-ray diffraction (XRD) techniques [66]. In general, it can analyze crystallized materials. XRD is used to determine the identity of crystalline solids based on their atomic structure. Diffraction occurs because $\mathrm{X}$-rays have wavelengths in the order of a few angstroms, which are about the same as the interatomic distances in crystalline solids. Up to now, small angle X-ray scattering (SAXS) and wide X-ray scattering (WAXS) derived from XRD technique have been adopted to analyze the fine structure of the superlattice of the self-assembled NPs. The group lead by Beaucage adopted two-dimensional (2D) SAXS and 2D WAXS to analyze the dispersion and orientations of organically modified MMT used as reinforcement for the HDPE matrix [67]. A researcher from the Air Force Research Laboratory, Ohio, USA, adopted SAXS to examine the structure of organically modified MMT dispersed in toluene and toluene-acetone blends, providing detailed information on the distribution of the stacks and characteristics of the intercalated crystallite [68]. In 2005, the research group lead by Zhu synthesized a semicrystalline polymer/layered silicate nano-composites by blending a solution of a low molecular weight PE oxide (PEO) with an organically modified MMT NPs. The intercalation morphology was studied by temperature-dependent synchrotron wideangle X-ray diffraction (WAXD). Significant secondary crystallization was observed in the PEO-MMT nanocomposites. Reversible deintercalation and intercalation processes were detected during secondary crystallization and subsequent melting of the secondary crystals. On the basis of the two dimensional WAXD results, an interphase layer between the MMT primary particles and PEO lamellar crystals was proposed.

Recently, more and more researches have adopted solid-state nuclear magnetic resonance (SSNMR) to characterize the NP dispersion in a polymer matrix. In 2001, a research group led by Van der Hart from the National Institute of Standards and Technology, Maryland, USA, adopted SSNMR to characterize the MMT in nylon matrix. They applied Fe atoms in the MMT to determine its dispersion in a polymer matrix [69]. Based on these results, they further characterized the phase transition of the MMT NPs and the crystallization process of the MMT within the polymer matrix [70]. EPR is another important analysis technique to characterize the interaction between NPs and a polymer matrix. For instance, researchers from the Max Planck In- stitute for Polymer Research, Mainz, Germany, used the EPR to directly measure and understand the interface between polymer and organically modified MMT NPs. During the characterization, the phenomenon was observed that some mobility of the MMT increased with the increasing temperature [71].

Surface structure and interaction between surface protecting ligands and atoms can be achieved by absorption spectroscopy, NIR, Fourier transform infrared spectrometry (FTIR) and Raman spectroscopy. In 2003, a research group led by Gleason from Massachusetts Institute of Technology utilized FTIR to study the $\mathrm{Si}-\mathrm{O}$ stretching peak and its peak shifts. This suggests a method to observe how MMT NPs deform relative to the polymer matrix [72]. In 2004, a research group from the U.S. Department of Energy led by Maupin characterized the MMT-PLA and MMT-PS composites. They used fluorescence dye (Nile Blue A) on imidazolium or ammonium treated MMT, and adopted laser-induced fluorescence spectroscopy as a probe to detect the interaction and exfoliation in nano-composites. As clay exfoliated in PLA, the color of nano-composites changed from purple to red, and spectra from the dye also changed [73].

\section{Problems and expectations}

Not only does the application of nanotechnology in food packaging bring convenience for daily life, it also enhances the development of nanotechnology from basic research to applied areas. However, to understand the migration properties of NPs in composites and toxicity, it is necessary for us to assess fully and effectively the safety of NPs used in food packaging \& contact materials. Recently, the U.S. Department of Agriculture and Food and Drug Administration (FDA), and the EU, conducted a brief assessment on NPs and NMs applied in various areas of industry. The relatively scarce scientific data on migration, exposure sources and toxicities indicate the difficulties and problems in properly understanding the nature of NPs. At present, the following problems are identified and need to be resolved to fully assess the safety of NPs in food packaging:

(1) More and effective separation and determination techniques are needed to develop and establish the matrix for nano-composites with paper and paperboard, glass and ceramics, and metals;

(2) Comprehensive physicochemical characteristics of the applied NPs should be established. These data include size, size distribution, inherent crystal structure, morphologies, surface ligand properties, surface charge, surface reactivity and the aggregation behaviors under different $\mathrm{pH}$ conditions;

(3) Establish the relationship between particle size, purity and toxicity;

(4) As a priority, a methodology needs to be established 
for determining and assessing the migration potential and process of NPs from food contact materials to packed food. Compared to the detection techniques for traditional small organic molecular and inorganic compounds, the skills required for the analysis of NPs are more sophisticated. In migration tests, the migratability of NPs in a matrix, dispersion in simulations and alterations in size and morphologies before and after the migration tests bring challenges for successful assessment of the safety of NMs;

(5) Develop an understanding of toxicity following oral intake of a wide range of NMs for which there is likely human exposure;

(6) Generate information on the toxico-kinetic properties of NPs after oral exposure and appropriate dose metrics in relation to the toxicity of NPs. Correlate these data with the physicochemical characteristics to see whether different NPs can be grouped. Generate information on the bioavailability from food and feed for a range of NMs and investigate potential accumulation in different organs and transport through the placenta and into milk. In addition, biotransformation and excretion should be addressed. Develop, improve and validate in silico, in vitro and in vivo test methodologies to assess toxicity of NPs.

The safety assessment of NPs and NMs does not imply restraining the application of NPs and NMs in the food industry. Before it extensively pervades people's daily life, it is very necessary for us to properly assess the safety of NMs. It is believed that the invention of new and novel detection techniques in the future will give the NMs a reasonable and justified evaluation, which undoubtedly can be considered as a warranty for the public to safely enjoy high technology products in the food industry.

1 Aitken R F, Hankin S M, Tran C L, et al. REFNANO: Reference Materials for Engineered Nanoparticle Toxicology and Metrology. Technical Report, Institute of Occupational Medicine. 2007

2 Bouwmeester H, Dekkers S, Noordam M, et al. Health Impact of Nanotechnologies in Food Production. Technical Report, RIKILTInstitute of Food Safety, Wageningen University and Research Centre. 2007

3 Torchilin V P. Targeted pharmaceutical nanocarriers for cancer therapy and imaging. AAPS J, 2007, 9: E128-E147

4 Moraru C I, Panchapakesan C P, Huang Q, et al. Nanotechnology: A new frontier in food science. Food Technol, 2003, 57: 24-29

5 Alexandra M, Dubois P. Polymer-layered silicate nanocomposites: Preparation, properties and uses of a new class of materials. Mat Sci Eng R, 2000, 28: 1-63

6 Peter Š, Qasim C, Dušan B. Migration of engineered nanoparticles from polymer packaging to food-A physicochemical view. J Food Nutr Res, 2008, 47:105-113

7 Repot of an OECD Workshop on Exposure Assessment and Exposure Mitigation: Manufactured Nanomaterials. Technical Report, OECD Environment, Health and Safety Publications, Series on the Safety of Manufactured Nanomaterials, No. 13, Organisation for Economic Co-operation and Development, Paris. 2009

8 Nanomaterials in REACH. Technical Report, Follow-up to the 6th Meeting of the REACH Competent Authorities for the implementation of Regulation (EC) 1907/2006 (REACH), Brussels. 2008
9 Kotsilkova R, Petkova V, Pelovski Y. Thermal analysis of polymersilicate nanocomposites. J Therm Anal Calorim, 2001, 64: 591-598

10 Ray S S, Maiti P, Okamoto M, et al. New polylactide/layered silicate nanocomposites. 1. Preparation, characterization, and properties. Macromolecules, 2002, 35: 3104-3110

11 Wang K K, Koo C M, Chung I J. Physical properties of polyethylene/silicate nanocomposite blown films. J Appl Polym Sci, 2003, 89: 2131-2136

12 Wan C, Qiao X, Zhang Y, et al. Effect of different clay treatment on morphology and mechanical properties of PVC-clay nanocomposites. Polym Test, 2003, 22: 453-461

13 Schartel B, Pötschke P, Knoll U, et al. Fire behaviour of polyamide 6/multiwall carbon nanotube nanocomposites. Eur Polym J, 2005, 41: $1061-1070$

14 Xu B, Zheng Q, Song Y, et al. Calculating barrier properties of polymer/clay nanocomposites: Effects of clay layers. Polymer, 2006, 47: 2904-2910

15 Aaron L B. "Nano, nano" food packaging technology. Food Technol, 2003, 57: 52-54

16 Jun S K, Eunye K, Kyeong N Y, et al. Antimicrobial effects of silver nanoparticles. Nanomed-Nanotechnol, 2007, 3: 95-101

17 Margaret I, Sau L L, Vincent K M P, et al. Antimicrobial activities of silver dressings: An in vitro comparison. J Med Microbiol, 2006, 55: 59-63

18 Mohammed F A, Balaji K, Girilal M, et al. Mycobased synthesis of silver nanoparticles and their incorporation into sodium alginate films for vegetable and fruit preservation. J Agric Food Chem, 2009, 57: 6246-6252

19 del N M, Cannarsi M, Altieri C, et al. Effect of Ag-containing nano composite active packaging system on survival of alicyclobacillus acidoterrestris. J Food Sci, 2004, 69: E379-E383

20 LaCoste A, Schaich K, Zumbrunnen D, et al. Advancing controlled release packaging through smart blending. Packag Technol Sci, 2005, 18: 77-87

21 Lopez-Rubio A, Gavara R, Lagaron J. Bioactive packaging: Turning foods into healthier foods through biomaterials. Trends Food Sci Technol, 2006, 17: 567-575

22 Nachay K. Analyzing nanotechnology. Food Technol, 2007, 61: 3436

23 Jin-Hae C, Yeong Uk A, Donghwan C, et al. Poly(lactic acid) nanocomposites: comparison of their properties with montmorillonite and synthetic mica (II). Polymer, 2003, 44: 3715-3720

24 Chow W S, Lok S K. Thermal properties of poly(lactic acid)/organo-montmorillonite nanocomposites. J Therm Anal Calorim, 2009, 95: 627-632

25 McGlashan S A, Halley P J. Preparation and characterisation of biodegradable starch-based nanocomposite materials. Polym Int, 2003, 52: 1767-1773

26 Avella M, De Vlieger J J, Errico M E, et al. Biodegradable starch/clay nanocomposite films for food packaging applications. Food Chem, 2005, 93: 467-474

27 Paul J A B, David R, Stephan H, et al. The potential risks of nanomaterials: A review carried out for ECETOC. Part Fibre Toxicol, 2006, 3: 1-35

28 Nemmar A, Vanbilloen H, Hoylaerts M F, et al. Passage of intratracheally instilled ultrafine particles from the lung into the systemic circulation in hamster. Am J Respir Crit Care Med, 2001, 164: 1665-1668

29 Kreyling W G, Semmler M, Erbe F, et al. Translocation of ultrafine insoluble iridium particles from lung epithelium to extrapulmonary organs is size dependent but very low. J Toxicol Environ Health A, 2002, 65: 1513-1530

30 Maibach H I, Feldman R J, Milby T H, et al. Regional variation in percutaneous penetration in man: Pesticides. Arch Environ Health, 1971, 23: 208-211

31 Lademann J, Richter H, Otberg N, et al. Application of a dermatological laser scanning confocal microscope for investigation in skin physiology. J Laser Phys, 2003, 13: 756-760

32 Pflücker $\mathrm{F}$, Wendel $\mathrm{V}$, Hohenberg $\mathrm{H}$, et al. The human stratum corneum layer: An effective barrier against dermal uptake of different 
forms of topically applied micronised titanium dioxide. Skin Pharmacol Appl Skin Physiol, 2001, 14(Suppl 1): 92-97

33 Alvarez-Roman R, Naik A, Kalia Y N, et al. Skin penetration and distribution of polymeric nanoparticles. J Control Release, 2004, 99: 53-62

34 Hoet P H, Bruske-Hohlfeld I, Salata O V. Nanoparticles-known and unknown health risks. J Nanobiotechnology, 2004, 2: 12-27

35 des R A, Fievez V, Garinot M, et al. Nanoparticles as potential oral delivery systems of proteins and vaccines: a mechanistic approach. J Control Release, 2006, 116: 1-27

36 Szentkuti L. Light microscopical observations on luminally administered dyes, dextrans, nanospheres and microspheres in the preepithelial mucus gel layer of the rat distal colon. J Control Release, 1997, 46: 233-242

37 Hillyer J F, Albrecht R M. Gastrointestinal persorption and tissue distribution of differently sized colloidal gold nanoparticles. J Pharm Sci, 2001, 90: 1927-1936

38 Jani P, Halbert G W, Langridge J, et al. Nanoparticle uptake by the rat gastrointestinal mucosa: Quantitation and particle size dependency. J Pharm Pharmacol, 1990, 42: 821-826

39 Samuel K, Lai D, O'Hanlon E, et al. Rapid transport of large polymeric nanoparticles in fresh undiluted human mucus. Proc Nat Acad Sci USA, 2007, 104: 1482-1487

40 Kim Y S, Kim J S, Cho H S, et al. Twenty-eight-day oral toxicity, genotoxicity, and gender-related tissue distribution of silver nanoparticles in Sprague-Dawley rats. Inhal Toxicol, 2008, 20: 575-583

41 Günter O, Eva O, Jan O. Nanotoxicology: An emerging discipline evolving from studies of ultrafine particles. Environ Health Persp, 2005, 113: 823-839

42 Donaldson K, Lang T C. Inflammation caused by particles and fibers. Inhal Toxicol, 2002, 14: 5-27

43 Halliwell B, Gutteridge J M C. Free Radicals in Biology and Medicine. Oxford: Oxford University Press, 1999

$44 \mathrm{Li} \mathrm{N}$, Sioutas C, Cho A, et al. Ultrafine particulate pollutants induce oxidative stress and mitochondrial damage. Environ Health Persp, 2003, 111: 455-460

45 Yamakoshi Y, Umezawa N, Ryu A, et al. Active oxygen species generated from photoexcited fullerene $\left(\mathrm{C}_{60}\right)$ as potential medicines: $\mathrm{O}^{2-*}$ versus ${ }^{1} \mathrm{O}_{2}$. J Am Chem Soc, 2003, 125: 12803-12809

46 Kedar N P. Can we prevent Parkinson's and Alzheimer's disease? J Postgrad Med, 2003, 49: 236-245

47 Calderón-Garcidueñas L, Reed W, Maronpot R R, et al. Brain inflammation and Alzheimer's-like pathology in individuals exposed to severe air pollution. Toxicol Pathol, 2004, 32: 650-658

48 Brown D M, Donaldson K, Borm $\mathrm{P}$ J, et al. Calcium and ROS-mediated activation of transcriptionfactors and TNF-alpha cytokine gene expression in macrophages exposed to ultrafine particles. Am J Physiol Lung Cell Mol Physiol, 2004, 286: L344-L353

49 Stone V, Johnson G D, Wilton J C, et al. Effect of oxidative stress and disruption of $\mathrm{Ca}^{2+}$ homeostasis on hepatocyte canalicular function in vitro. Biochem Pharmacol, 1994, 47: 625-632

50 Matthew J, Campen J D, McDonald, et al. Cardiovascular effects of inhaled diesel exhaust in spontaneously hypertensive rats. Cardiovasc Toxicol, 2003, 3: 353-361

51 Suwa T, Hogg J C, Quinlan K B, et al. Particulate air pollution induces progression of atherosclerosis. J Am Coll Cardiol, 2002, 39: 935-942

52 Andrej $\mathrm{K}$, Andreas S, Shinji $\mathrm{T}$, et al. Ultrafine particles exert prothrombotic but not inflammatory effects on the hepatic microcirculation in healthy mice in-vivo. Circulation, 2004, 109: 1320-1325

53 Lomer M C, Thompson R P, Powell J J. Fine and ultrafine particles of the diet: Influence on the mucosal immune response and association with Crohn's disease. P Nutr Soc, 2002, 61: 123-130

54 Lomer M C, Grainger S L, Ede R, et al. Lack of efficacy of a reduced microparticle diet in a multi-centred trial of patients with active Crohn's disease. Eur J Gastroen Hepat, 2005, 17: 377-384

55 Powell J J, Harvey R S, Ashwood P, et al. Immune potentiation of ultrafine dietary particles in normal subjects and patients with inflammatory bowel disease. J Autoimmun, 2000, 14: 99-105

56 Gurr J R, Wang A S, Chen C H, et al. Ultrafine titanium dioxide particles in the absence of photoactivation can induce oxidative damage to human bronchial epithelial cells. Toxicology, 2005, 213: 66-73

57 Landsiedel R, Kapp M D, Schulz M, et al. Genotoxicity investigations on nanomaterials: Methods, preparation and characterization of test material, potential artifacts and limitations-many questions, some answers. Mutat Res, 2009, 681: 241-258

58 Mroz R M, Schins R P, Li H, et al. Nanoparticle-driven DNA damage mimics irradiation-related carcinogenesis pathways. Eur Respir J, 2008, 31: 241-251

59 Rahman Q, Lohani M, Dopp E, et al. Evidence that ultrafine titanium dioxide induces micronuclei and apoptosis in syrian hamster embryo fibroblasts. Environ Health Persp, 2002, 110: 797-800

60 Papageorgiou I, Brown C, Schins R, et al. The effect of nano- and micron-sized particles of cobalt-chromium alloy on human fibroblasts in vitro. Biomaterials, 2007, 28: 2946-2958

61 Alexander B M, Jeffrey W G. Characterization of polymer-layered silicate (clay) nanocomposites by transmission electron microscopy and X-ray diffraction: A comparative study. J App Polym Sci, 2003, 87: 1329-1338

62 Vermogen A, Masenelli-Varlot K, Seguela R, et al. Evaluation of the structure and dispersion in polymer-layered silicate nanocomposites. Macromolecules, 2005, 38: 9661-9669

63 Usuki A, Hasegawa N, Kadoura H, et al. Three dimensional observation of structure and morphology in nylon-6/clay nanocomposite. Nano Lett, 2001, 1: 271-272

64 Perrin-Sarazin F, Ton-That M T, Bureau M N, et al. Micro- and nano-structure in polypropylene/clay nanocomposites. Polymer, 2005, 46: 11624-11634

65 Yalcin B, Cakmak M. The role of plasticizer on the exfoliation and dispersion and fracture behavior of clay particles in PVC matrix: A comprehensive morphological study. Polymer, 2004, 45: 6623-6638

66 Vaia R A, Liu W. X-ray powder diffraction of polymer/layered silicate nanocomposites: Model and practice. J Polym Sci B: Polym Phys, 2002, 40: 1590-1600

67 Bafna A, Beaucage G, Mirabella F, et al. 3D hierarchical orientation in polymer-clay nanocomposite films. Polymer, 2003, 44: 1103-1115

68 Vaia R A, Liu W, Koerner H. Analysis of small-angle scattering of suspensions of organically modified montmorillonite: Implications to phase behavior of polymer nanocomposites. J Polym Sci B: Polym Phys 2003, 41: 3214-3236

69 VanderHart D L, Asano A, Gilman J W. Solid-state NMR investigation of paramagnetic nylon-6 clay nanocomposites. 1. Crystallinity, morphology, and the direct influence of $\mathrm{Fe}^{3+}$ on nuclear spins. Chem Mater, 2001, 13: 3781-3795

70 VanderHart D L, Asano A, Gilman J W. Solid-state NMR investigation of paramagnetic nylon-6 clay nanocomposites. 2. Measurement of clay dispersion, crystal stratification, and stability of organic modifiers. Chem Mater, 2001, 13: 3796-3809

71 Jeschke G, Panek G, Schleidt S, et al. Addressing the interface in polymer- clay nanocomposites by electron paramagnetic resonance spectroscopy on surfactant probes. Polym Eng Sci, 2004, 44: 1112-1121

72 Loo L S, Gleason K K. Fourier transform infrared investigation of the deformation behavior of montmorillonite in nylon-6/nanoclay nanocomposite. Macromolecules, 2003, 36: 2587-2590

73 Maupin P H, Gilman J W, Harris R H, et al. Optical probes for monitoring intercalation and exfoliation in melt-processed polymer nanocomposites. Macromol Rapid Commun, 2004, 25: 788-792

Open Access This article is distributed under the terms of the Creative Commons Attribution License which permits any use, distribution, and reproduction in any medium, provided the original author(s) and source are credited. 